\title{
Innovations in microfinance technologies
}

Gisèle Gagnon

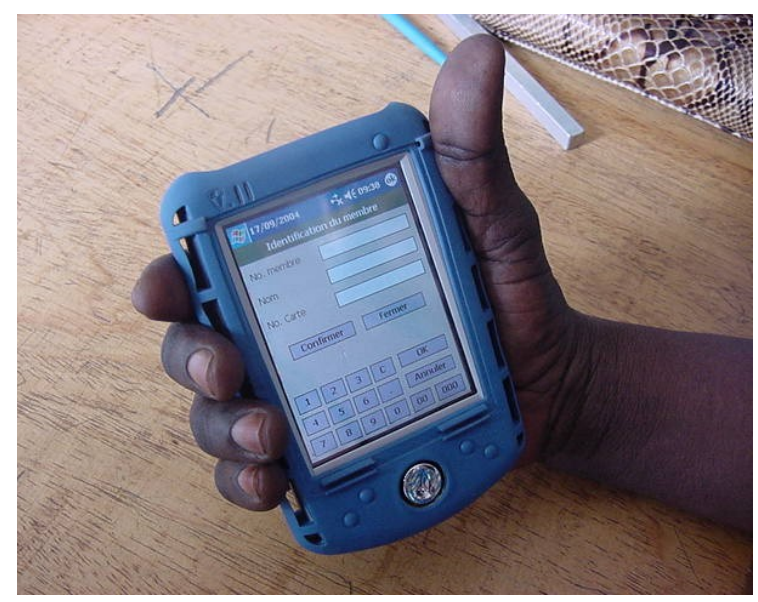

January 2007 



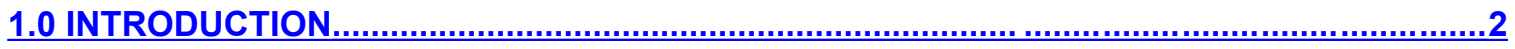

2.0 REASONS FOR INTRODUCING TECHNOLOGY ............................................................

3.0 GOALS FOR INTRODUCING TECHNOLOGY ..............................................................

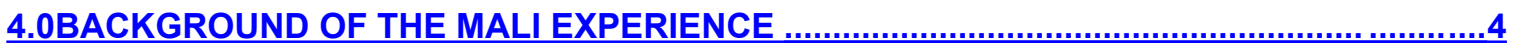

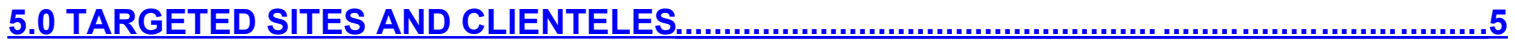

$\underline{6.0}$ BUSINESS STRATEGY LINKED TO TECHNOLOGY....................................................

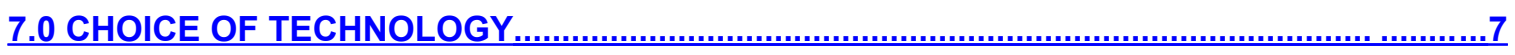

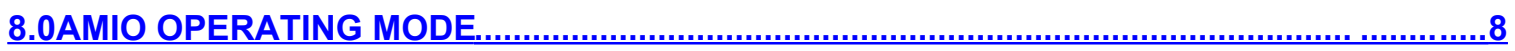

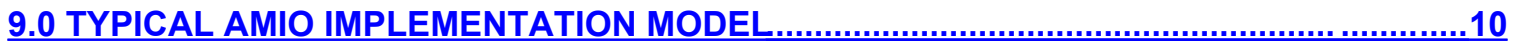

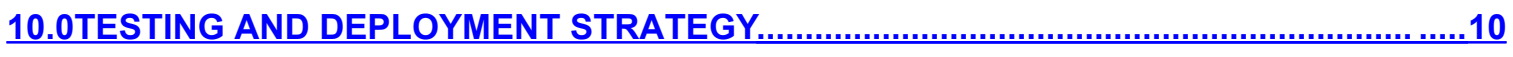

11.0 PERSONNEL INVOLVED, TRAINING AND COACHING ...............................................11

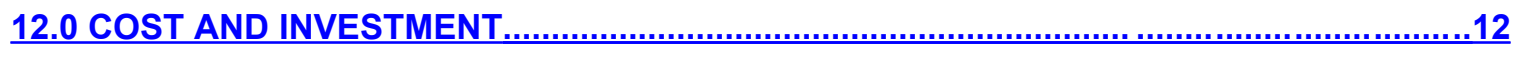

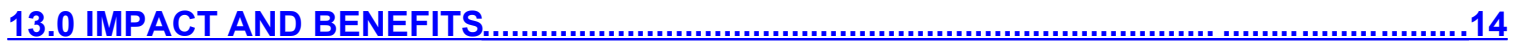

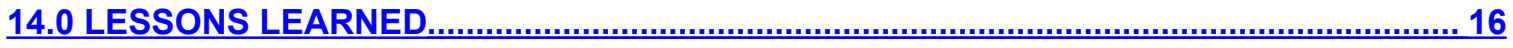

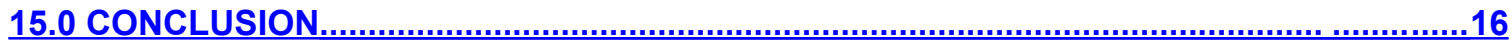

List of figures

FIGURE 1 EXAMPLE OF THE NYĖSIGISO NETWORK STRUCTURE...................................4

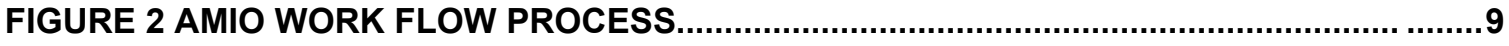

List of tables

TABLE 1 CHANGE: 3 YEARS AFTER COMPUTERIZATION

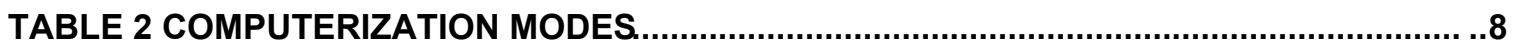

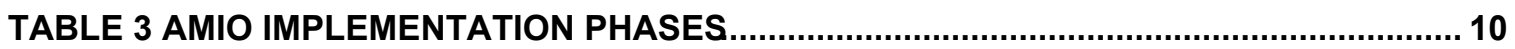

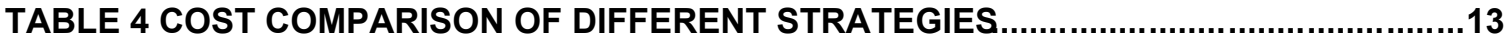





\section{Starting with a look at what is happening in Mali...}

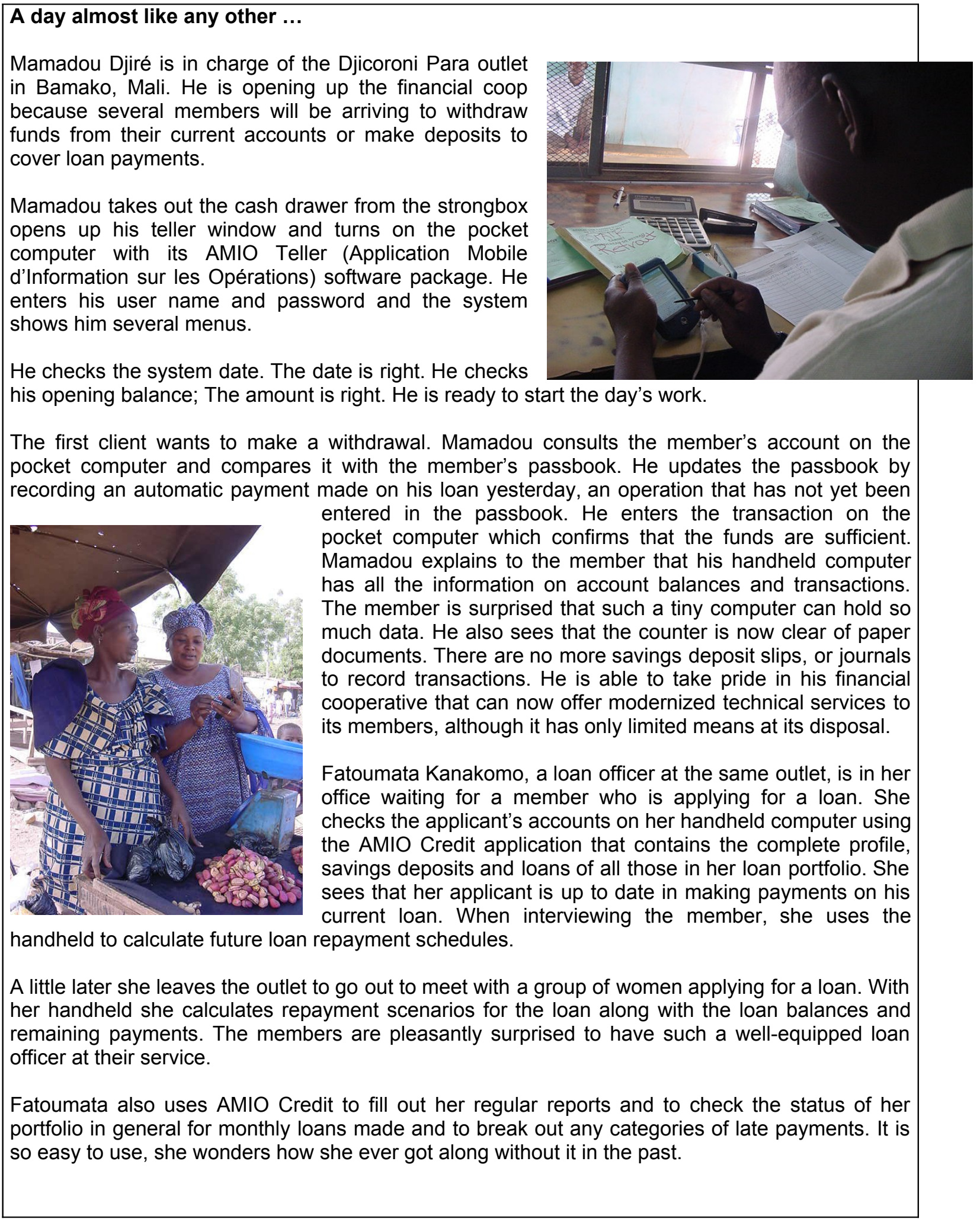




\subsection{Introduction}

Today, throughout the developing world, over $80 \%$ of the population still does not have access to financial services. Yet this access is not a privilege. It is a necessity for all.

In order to make basic financial services available to all and to provide coaching to clients as their needs grow, financial institutions need to diversify their approach. Opening the right door at the right time is what Développement international Desjardins has been doing for the last 35 years by working in the field of community-based finance.

Développement international Desjardins (DID) is a Canadian organization that specializes in providing technical support and investment in the field of community finance for developing and emerging nations. DID is currently providing support to community financial institutions in twenty countries in Africa, Latin America, the Caribbean, Asia and Eastern and Central Europe. DID's partners as a whole provide financial services to over 3.2 million people, employ nearly 6,150 , have deposits worth CAN $\$ 860$ million and hold assets worth over CAN $\$ 1.1$ billion.

Through its various types of intervention, DID strives to empower the disadvantaged by encouraging control over community-owned and oriented financial institutions. The expertise of DID's 100 employees is called on to set up base institutions, network them, introduce new financial products, turn around crisis situations, modernize operations, design supervision strategies, draw up legislation governing savings and credit cooperatives and train various actors working in the community financial scene.

DID is a subsidiary of the Desjardins Group, the largest financial cooperative in Canada.

This document describes the process undertaken in Mali (between September 2003 and December 2005) to introduce mobile banking technologies using handheld computers. It identifies the basic elements used to develop and introduce the system into an expanding microfinance institution striving to reach members in remote rural areas. The impact and benefits are also mentioned in order to provide a portrait of the advantages that technological innovation can offer an organization.

More than a test trial, this was a business solution that was well integrated into the growth of the microfinance institution (MFI) since computerization of the operations had become crucial for the development of MFIs in search of new outreach methods.

Aspects of computerization using the banking software will not be addressed in detail but computerization does constitute a prerequisite for introducing mobile technologies. This document will focus on handheld technologies along with the opportunities and challenges associated with their introduction into microfinance institution networks.

\subsection{Reasons for introducing technology}

Before addressing the subject of project execution, it is useful to recall the reasons behind microfinance network modernization. Technology is designed to:

- Automate operations, the basis of the services delivered to members. Technology increases the number of transactions with the knowledge that transaction tools and systems accelerate operations, and improve the quality of operations by reducing errors that are time-consuming to seek out and correct.

- Reach urban and rural clients more extensively, while maintaining service quality and avoiding costly infrastructure investment. 
- Stand out from the competition and modernize the network image, offering a safe, agreeable environment attracting new members, who are reassured by the technology used to manage their assets.

- Quickly obtain all information required for management, to gauge performance and make proper, timely decisions. Technology assists in obtaining better knowledge of the clientele and their needs, of sites and their productivity, products and their popularity, all the data vital for the survival of an organization.

The added value provided by banking software is obvious when the right conditions are present. Any project launched by an MFI must include the required human and material resources to handle the deployment of the new technologies after technical assistance comes to an end. Based on a before and after study of implementation, it is possible to estimate certain indicators measuring business growth and cost reductions over a three year time frame per employee. These include the following.

Table 1 Change: 3 years after computerization

\begin{tabular}{|l|c|c|c|}
\hline \multicolumn{1}{|c|}{ Efficiency gains } & Year 1 & Year 3 & Change \\
\hline Average number of members per employee & 559 & 747 & $34 \%$ \\
\hline Average assets per employee & $49,636,310$ & $88,496,162$ & $78 \%$ \\
\hline Number of transactions per employee (annual) & 8,412 & 9,557 & $14 \%$ \\
\hline Number of loans made per loan officer & 457 & 627 & $37 \%$ \\
\hline Loan portfolio per loan officer & $105,334,918$ & $178,923,341$ & $70 \%$ \\
\hline Portfolio at risk (PAR) 90 days(end of period) & $0.70 \%$ & $0.32 \%$ & $-54 \%$ \\
\hline
\end{tabular}

The bottom line is that technology increases productivity, while reducing errors and portfolio risk.

\subsection{Goals for introducing technology}

Specific goals were set for the introduction of mobile technologies, so that the effort invested would produce a significant impact on the population. These goals were to:

- Increase member access to coop products and services by bringing products and services closer to the poor in remote villages. Loan officers in 11 mother coops (about 40 employees) were equipped with mobile technologies. The reconfiguration of base coops and the creation of small-scale outlets and mobile operators offered obvious opportunities since these efforts reached a clientele that was often excluded from computerization projects due to the low volume of operations. This low level of activity however is often linked to the organizational isolation of the service outlet despite the fact that it is located in a zone with a high concentration of those requesting adapted services.

- Increase operational and financial site effectiveness, in the base financial cooperatives, the mother coops and the outlets. The project is designed to equip 25 outlets in the new structure with mobile technologies.

- Increase management and decision-making skills, by equipping coop and Union personnel and directors for decision making. This involves making information available quickly either directly or on printouts.

- Work within the existing infrastructure, if banking software had already been successfully implemented at some sites, mobile technologies would have to meet a specific need and fit in with the strategic directions taken. 
- Use technologies that would be easy to introduce and manage over time. The complexity of modern networks calls for critically important technical expertise that is often lacking in developing nations. The time required to prepare operators to run the system for daily operations can be long and costly. Partner autonomy after technical assistance comes to an end is also a major concern since mobile technologies are new and not extensively used by financial institutions. There were obviously major challenges facing the project over its 27 month implementation period.

\subsection{Background of the Mali experience}

The Nyèsigiso network in Mali is composed of savings and credit cooperatives in a two-tier set up that includes a Central Union and 11 mother coops (with 25 associated outlets) along with a specialized service for a business clientele. The geographic range of the network, with two urban centers (Bamako and Ségou) and several entities in rural zones, is representative of other MFI networks in West Africa. The following figures offer a glance at the size of its operations:

- Number of members: 125,000

- Number of borrowers: 24,000

- Volume of deposits: US $\$ 10$ million

- Volume of loans: US \$11 million

- Total assets: US \$15million

In 2004, the network undertook a vast reconfiguration project that gradually reduced the number of its units from 48 base coops down to only 11 mother coops and about 25 local or mobile outlets. These institutional and organizational changes were needed for integrated financial management of the financial coop network and for improved performance while still providing proactive competitive and specialized services through strong business units.

\section{Figure 1 Example of the Nyèsigiso network structure}

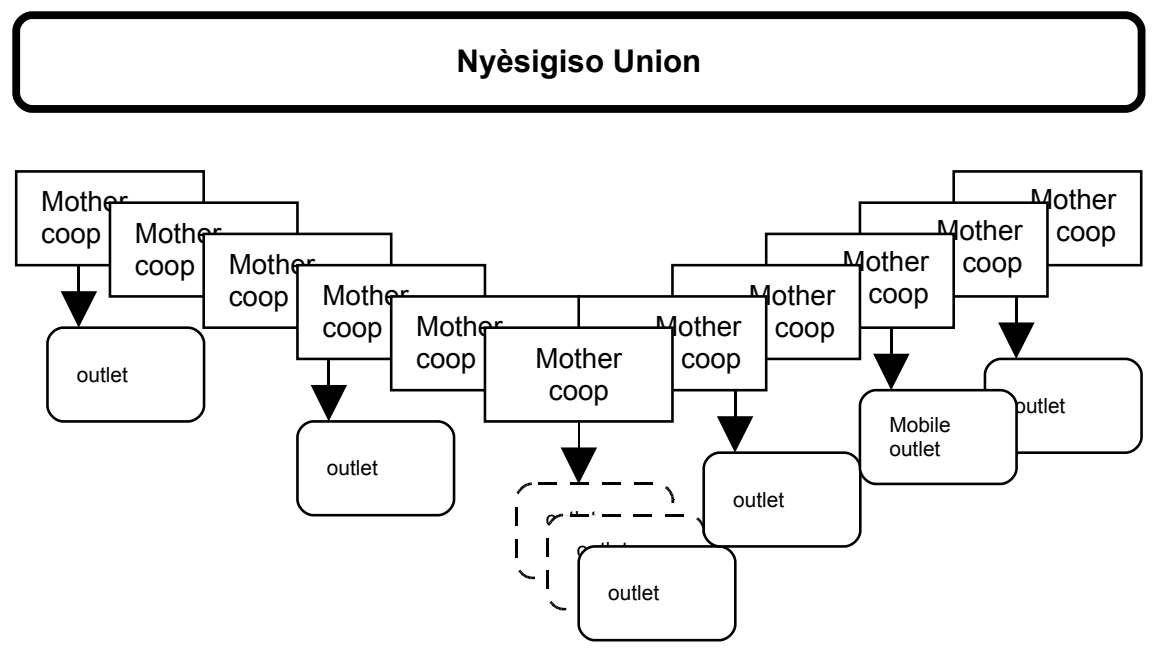


With support from DID and USAID, the Nyèsigiso network enjoyed two years of collaboration from Canadian advisors to develop and test mobile technologies needed to complement the computer systems already in place. Computerization of the coops had begun in 2002 with the introduction of the SAF banking software and the establishment of data processing centers. With support provided by DID, the locally based computerization team developed expertise in converting manual operations into computerized operations. The Low cost technologies to promote economic development of the poorest project was built on this foundation.

\section{SAF2000}

SAF2000 is a banking software package running under Windows, which uses a client-server architecture. It has several modules corresponding to the various needs of a financial institution. This system facilitates data integration from manual systems and easily adapts to the various phases of MFI expansion.

There were many factors that explain the success of this project and some of the most important were:

- A management team that was mobilized to place priority on the computerization project and assign the resources needed for its success.

- The interest in computerization exhibited by the staff in the mother coops and the outlets, especially for modernizing their job tasks.

- The dynamic outlook of the directors who understood the doors that computerization would open for all their members, even the poorest and most remote.

These factors contributed greatly to facilitating the introduction of crucial change that was unprecedented for its innovative character and potential impact. It should be added that the Nyèsigiso reconfiguration environment included coop closings and amalgamations, staff cutbacks and readjusted products and services that could have had an adverse affect on project success. However, Nyèsigiso adapted to the changing circumstances while maintaining its goal of delivering stable systems and making a significant contribution to network expansion.

\subsection{Targeted sites and clienteles}

Mobile technologies were delivered to two distinct groups of workers:

- Tellers whose main tasks are to handle member operations at the financial cooperative or in the field. These workers were given handhelds running AMIO Teller.

- Loan officers who approve loans and manage a loan portfolio either inside the financial cooperative or out in the field. They use handhelds running AMIO Credit.

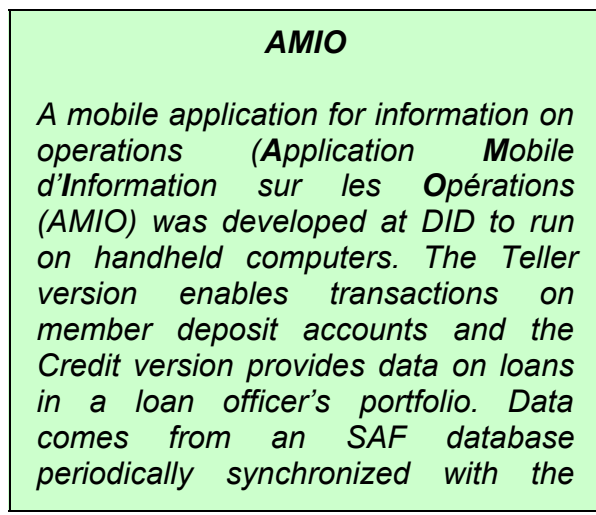

For optimum handheld use and impact on operations, the sites selected for implementation of AMIO Teller had to fit specific criteria:

- At least 50 transactions per day so that the volume of operation justifies the cost of handheld acquisition and processing expenses.

- No more than two tellers. More than two tellers presupposes a rather large volume of operations and the computerization option should be to use a desktop with the required peripherals. 
- Convert SAF database operations so that data can be regularly loaded into AMIO Teller. It should be noted that in June 2004, most Nyèsigiso sites that were computerized used a processing center and this meant that there were no computers on site in the coop. Coops sent data daily to the Union's data processing center where it was entered in off-line batch mode into the SAF database which then produced management reports for coop managers. The coops continued to run client-member transactions manually.

Loan officers received handhelds running AMIO Credit according to the following criteria:

- Loan officers should have at least 100 loans in their portfolio so that the handheld offers added value to the task of granting and recovering loans.

- Loan portfolios are managed using SAF banking software at sites that have converted their operations into processing centers (same prerequisite for AMIO Teller).

These few implementation criteria made it possible to target sites and ensure an environment that would quickly lead to tangible benefits. Since mobile technologies do have significant acquisition and implementation costs, an increase in membership and volume of borrowers was required. Sites were also selected for financial health, viability and development potential.

\subsection{Business strategy linked to technology}

During the reconfiguration process that involved uprooting and reorganizing many financial cooperatives along with opening up larger scale mother coops, Nyèsigiso linked computerization using mobile technology to its modernization plan.

More specifically, taking advantage of the innovations introduced by handheld computers and the visibility they offered, specific business orientations were defined as follows:

- Equip the small-scale outlets in various communities with handhelds and AMIO Teller so that poor populations in these areas could benefit from technology within their community and place of work. At the same time, members with greater wealth were targeted since there is greater confidence in a computerized outlet even if computerization only involves a small handheld computer.

- Convert some of the base coops into mobile outlets in order to continue to deliver services to regions while cutting costs. This approach involves sending out a teller with a handheld and cash drawer, one or two days per week into a village (usually on market day) in order to provide transaction services. The teller is often accompanied by a loan officer. No longer is there a need for a brick and mortar facility with a permanent staff for populations to receive service right in their own milieu.

- Reduce administrative costs charged to members since the costs linked to handheld equipment and implementation are lower in relation to desktops that require air conditioning and stable electric power.

- Save time through the greater efficiency of handheld operations and use the time recovered to raise awareness among communities for MFI products and services and recruiting new members.

- Accelerate the amalgamation process of base coops (into mother coops and small-scale outlets) by using mobile technologies as incentives to lead directors into making the organizational decisions required (such as accepting amalgamation with another financial cooperative). Computerization and handheld use are designed only for sites converted into mother coops, small-scale outlets or mobile outlets. 


\subsection{Choice of technology}

One of the most important phases in the project was to select the hardware platform for AMIO software development. This involved identifying the most promising technologies used in the handheld sector as well as those that are the most available in West Africa. Ideally, hardware should be purchased from local suppliers in order to ensure supply, service and maintenance of the equipment.

A study completed in early 2004 showed that there was a variety of choice for handhelds. There are two major types of handhelds, one running the PALM operating system (OS) and the other, the WINDOWS Mobile operating system.

Handhelds running the PALM OS are known as PalmPilots by the original equipment manufacturer. Handhelds running WINDOWS are known as PocketPCs. The main criteria guiding the final choice were:

- Ruggedness: The device must withstand heat, dust and shock since it will be used by newly trained staff in remote areas in the field.

- Powerful processing and storage capacity in order to support applications for simple banking transactions and consulting large databases.

- Ergonomics: User-friendly for staff not accustomed to computer use is a criteria that most handhelds fulfill.

- Power autonomy: Integrated rechargeable power source. Handhelds are used in remote areas where power is not always available. Handhelds running on integrated power sources are more economical for use than those requiring battery changes. Handhelds with integrated power sources are recharged when placed in their cradle.

- Operating system: Applications developed will be used to communicate off-line with applications in a Windows 2000 environment and an SQL database server (SAF).

Pocket PC (Windows Mobile) technology was selected using HP iPAQ units which are widely available and easily provided by local suppliers. Most criteria were met and prices were comparable between Palm Pilot and Pocket PC models even in West Africa.

The development method for AMIO Teller and AMIO Credit followed a typical process which led to the following main achievements:

- A preliminary analysis to identify the context, tools, user needs, risks and constraints.

- A functional analysis detailing all operations and interrelations. All special features of the SAF banking system were taken into account as were program parameters since the software would be the data source for Pocket PC applications.

- $\quad$ System and user tests performed in the field with future operators. 


\subsection{AMIO operating mode}

To facilitate understanding the following table illustrates how the various tools are implemented:

Table 2 Computerization modes

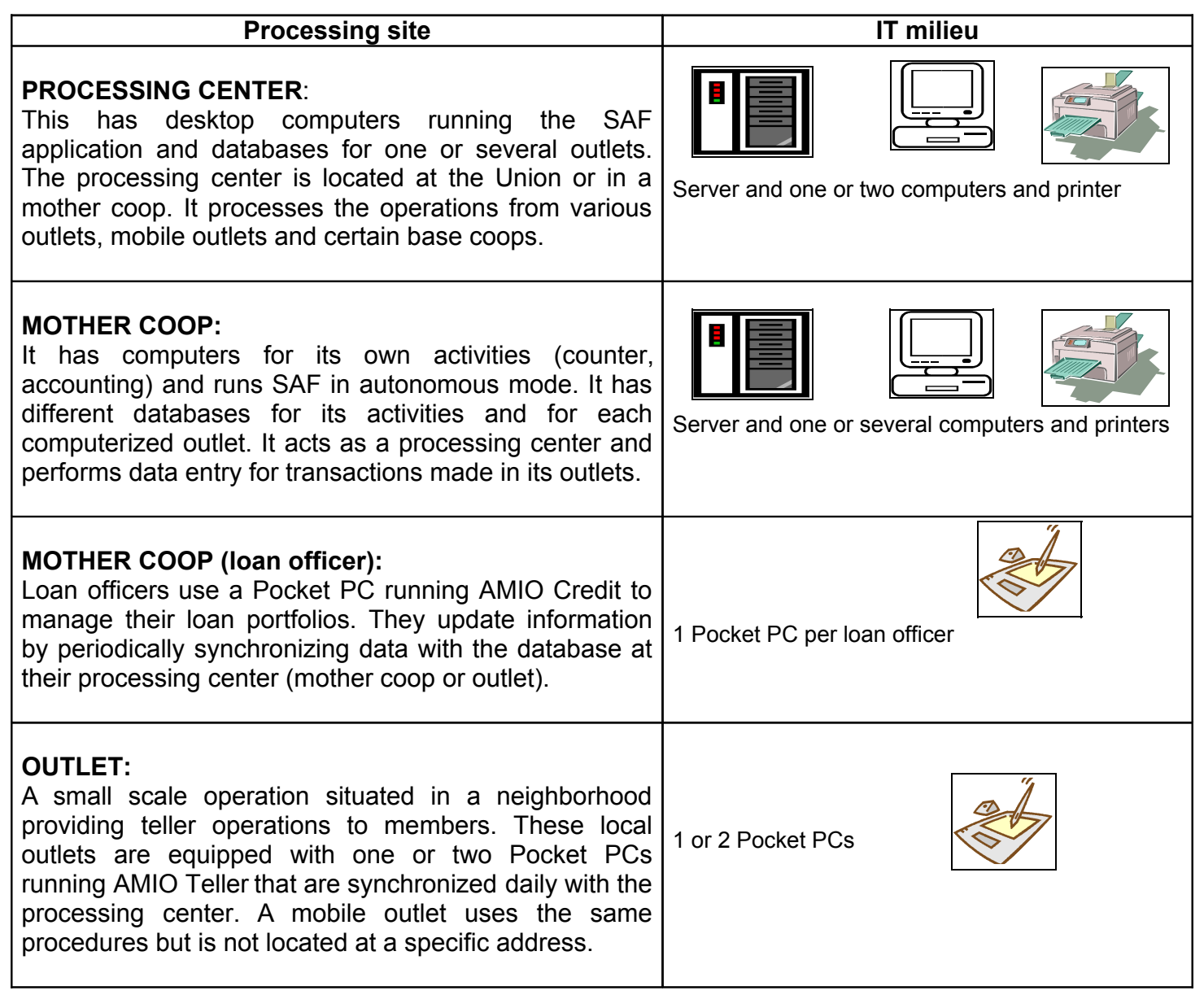

The following figure shows the interrelations established among the various systems and explains the process surrounding AMIO Teller operations and Pocket PC data synchronization: 
Figure 2 AMIO work flow process

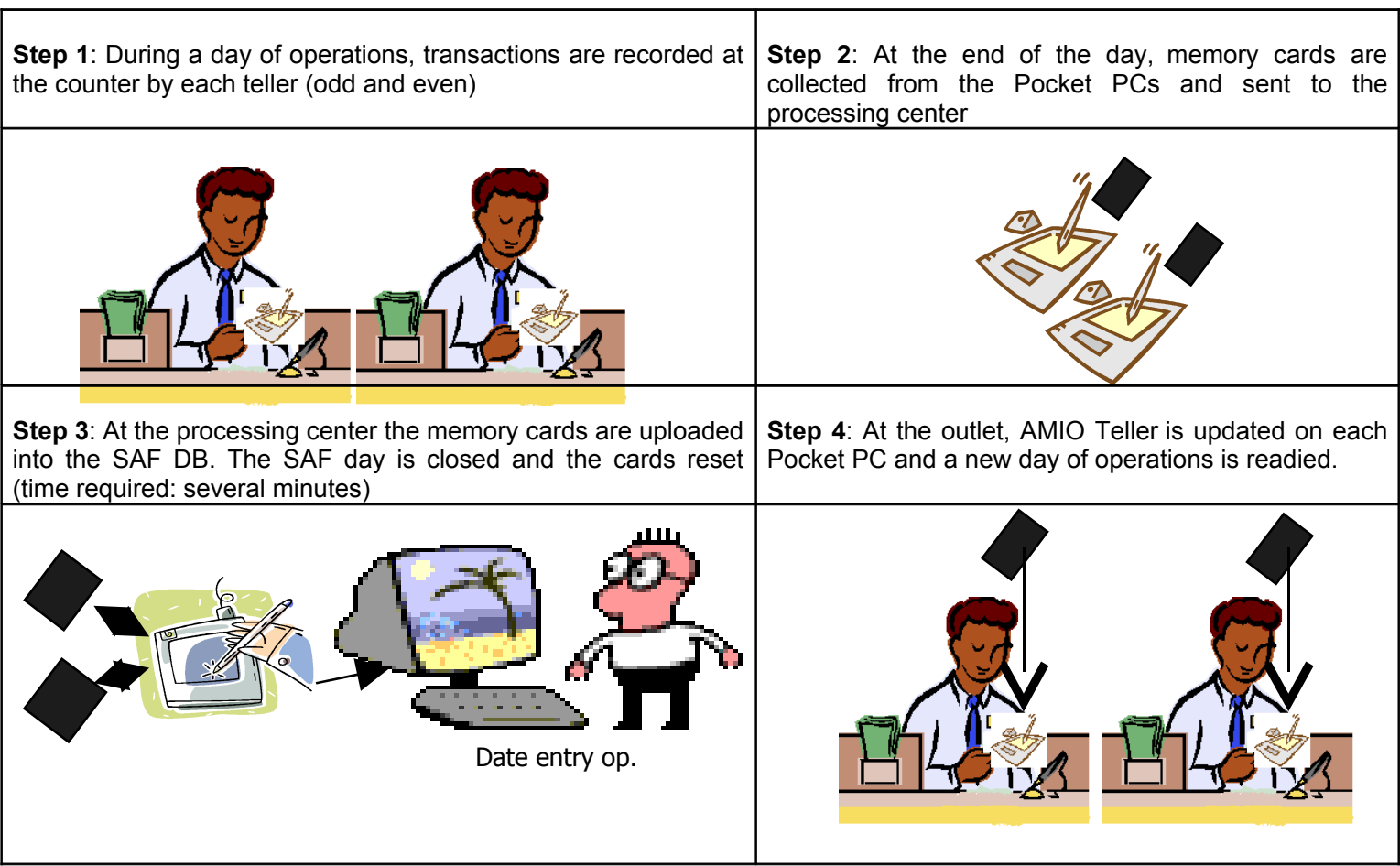

The various functionalities included in AMIO applications are as follows:

AMIO Teller: Performance of various teller operations which are then uploaded to SAF at the end of the day:

- Management of daily cash: view balance, transfers to strongbox, cash deficit or surplus

- Transactions with members: view balances and movements in all accounts, deposits, withdrawals, debit and credit notes

- Accounting transactions: inflows and outflows of funds

- Memory card uploads: daily operations are saved on memory cards for subsequent synchronization with processing center database

- Security management: modification of passwords

- Configuration management: modification of some parameters

AMIO CREDIT: Consultation of the savings deposits and the loans of borrowers assigned to a specific loan officer. No transactions allowed on accounts.

- Consultation of savings accounts: consultation of balances and movements in the savings accounts

- Consultation of loans: verification of movements in loan accounts, overdue payments, reimbursement schedules

- Simulated reimbursement schedules: input variables and see amortization tables

- Display various lists and reports: list of assigned borrowers, outstanding loans, overdue loans, loan portfolio overview, \% overdue in number and volume of credit

- Management of security: modification of password 


\subsection{Typical AMIO implementation model}

Introducing Pocket PCs and AMIO applications requires a review of usual strategies since the ease and facility of use mean that the implementation process is greatly reduced and user support simplified.

By excluding program development activities requiring weeks of work, the following are the main phases for AMIO implementation according to each category of personnel and taking into account whether or not the site already uses an SAF database:

Table 3 AMIO Implementation Phases

\begin{tabular}{|l|}
\hline \multicolumn{1}{c|}{ Activities } \\
\hline $\begin{array}{l}\text { 1) Preparation of hardware and configuration of the application for the site } \\
\text { and for each employee }\end{array}$ \\
\hline 2) Configuration of the SAF database at the processing center \\
\hline 2) Employee training on Pocket PCs \\
\hline 3) Employee training on AMIO Teller or Credit functionalities \\
\hline 4) Startup of operations with members and on-site support \\
\hline
\end{tabular}

The ease of implementation and preparation along with the rapid pace of assimilation by users constitute very interesting benefits in comparison to the usual complexity associated with desktop systems and the difficulties linked to training with conventional software packages.

\subsection{Testing and deployment strategy}

Due to the novelty of mobile technologies in West Africa and the uncertainty over acceptance by members and operators the AMIO Teller system was tested in a pilot project where certain conditions were present, namely:

- Employees who were dynamic (counter and teller supervisor, processing center operators) able to handle a series of adjustments and uncertainties

- Directors who were dynamic and members able to accept temporary disruption of operations

- Representative character of the site, namely an outlet with a number of daily transactions enabling system performance testing. In the case of the Djicoroni Para financial cooperative, the number of daily transactions over the counter in direct contact with members was 70 per day (for the 2 tellers).

- Close proximity with the Union data processing team (less than $3 \mathrm{~km}$ away) to facilitate rapid intervention and help. The computer systems team was experienced and had good technical knowledge.

The 3-month pilot project allowed verification of the hypotheses involving system architecture, its capacity and the performance and ruggedness of the Pocket PC units. In addition, the receptiveness of members and their comments contributed to success as did conversations with the employees involved who performed transactions using the Pocket PCs and AMIO Teller.

A pilot project was also organized for AMIO Credit, with 3 loan officers at three different sites which permitted assessment of the programs and a new Pocket PC model that had just been released by HP (iPAQ 2410). We have observed that models change so frequently that it is necessary to retest for performance and stability before deployment. In the case of the AMIO 
Credit pilot project, the activities were easy considering that the experience acquired with the AMIO Teller pilot project was more complex in terms of functionality.

After being reassured about system and unit capacity, the expected impact and benefits, as well as the simplicity of introduction and the receptivity of operators, the project team decided to undertake deployment and a calendar was established taking into account the conditions for implementation already established (see section 5). In the Nyèsigiso environment, the strategic orientations offered a suitable field of operation and the amalgamation of the coops and restructuring led to the creation of mother coops and mobile outlets.

The deployment goal was to fully computerize a group of coops (mother coop and its outlets) and ensure a technician to provide user support and system administration.

This strategy was made necessary due to the remoteness of certain sites and the importance of making them technologically self-sufficient. All support activities also had to be possible at a distance when a skilled employee was on site and linked to the information technologies (IT) team in the capital. Using Pocket PC technologies, this approach is all the more critical for remote sites since for the moment it is impossible to call on the services of local independent technicians (external suppliers) to provide emergency services for systems that are too new and not widespread.

In addition, the tests involved the transfer of skills to the local technical team. In this case technicians were trained to install AMIO software, configure Pocket PC units and provide user support services. This aspect was covered during deployment at the second site since the pilot project was specifically focused on assessing the hardware and software and the training strategy for operators. The ease of introduction was observed and the local IT team quickly became proficient with the installation methodology and configuration.

\subsection{Personnel involved, training and coaching}

The personnel associated with the development project and the introduction of new technologies are a major concern due to the instability that the test could create among the members and staff. The expertise and effort required also led to various adjustments in the project team which involved the following collaboration:

- Managers in the Nyèsigiso network approved activities and made staff available for the work. An IT committee periodically reviewed the work and did all possible to facilitate project team efforts. A communication plan was set up to inform the overall staff and directors on progress with these new technologies, a first in West Africa.

- The staff at the pilot sites participated in assessing the needs and the functionalities and the pre-implementation tests. These employees also actively participated in the pilot project to identify technical problems, support the work organization review and collaborated in evaluating this real world experiment.

- The local IT team was involved very directly in order to influence the developments that needed to be adapted to the technical environment already set up. Moreover, as they were already the champions of these technologies and attention was riveted on them, a recruiting effort made it possible to add additional complementary staff planned in the IT project. It should be noted that the local IT team did not develop applications (this was done at DID) but did install and configure them and provide operator support.

The training delivered was supported with material produced specifically for each tool and the simplified design, like the Pocket PC and its programs, facilitated knowledge transfer. A specific half-day session was planned to demystify Pocket PC use, managing power, backup batteries, use of the stylus, data security and the unit itself. Another half-day was devoted to the AMIO programs (Teller or Credit according to the staff involved) their functionalities, saving data and periodic synchronization. 
One of the particularities of these systems is that the operator does not need to be familiar with office productivity tools (such as a Windows interface and navigation, etc) to be able to use a Pocket PC. Navigation using a stylus and menus is so natural that even illiterate operators who have mastered numbers and simple calculations can run the system.

This constitutes a major advantage in relation to computerization using a desktop that requires much more complex operations.

Each AMIO Teller implementation was followed by a period of coaching for each teller in their daily tasks over several days. Here again, the simplicity of the tool greatly reduced the interventions required and the tellers quickly become fully autonomous. Moreover, at each daily visit to the processing center to synchronize data with the SAF DB, operators could obtain support from the data input operators if problems appeared.

The AMIO Credit application mainly offers screen shots of data and coaching was even easier. Loan officers quickly became autonomous and a personalized follow up was given each when requested. They met together after a month's use to review the content of their loan portfolios and check if all the functionalities were being properly used.

\subsection{Cost and investment}

In order to assess the impact of introducing Pocket PC technologies and their benefits, they had to be measured in relation to the costs involved in the effort. An analysis on one small-scale site implementation can be done using two scenarios: computerization in autonomous mode using a desktop and SAF software for teller and accounting operations or computerization using AMIO Teller. We do not take into account development costs that have been subsidized but we do take into account the cost of all materials, software and staff. 
Table 4 Cost comparison of different strategies

\begin{tabular}{|l|c|c|}
\hline \multicolumn{1}{|c|}{ Cost generating items } & \multicolumn{1}{|c|}{$\begin{array}{c}\text { Single SAF desktop } \\
\text { environment } \\
\text { (3 employees) }\end{array}$} & $\begin{array}{c}\text { Two PocketPC AMIO } \\
\text { Teller environment } \\
\text { 3 employees }\end{array}$ \\
\hline a) Desktop computer & \$USD & \$USD \\
\hline b) Power inverter & 3500.00 & 0 \\
\hline c) Laser printer & 900.00 & 0 \\
\hline d) SAF license & $1,400.00$ & 0 \\
\hline e) Air conditioner & 950.00 & 0 \\
\hline f) Power generator & $5,800.00$ & $\mathbf{0}$ \\
\hline Subtotal & $\mathbf{1 1 , 6 0 0 . 0 0}$ & 0 \\
\hline g) Renovations & $1,000.00$ & $2,000.00$ \\
\hline h) PocketPC and peripherals & 0 & $2,300.00$ \\
\hline $\begin{array}{l}\text { i) PC used at processing center } \\
\text { for database management }\end{array}$ & & 30.00 \\
\hline j) SAF and Office training & 230.00 & 30.00 \\
\hline \multicolumn{1}{|l|}{ k) Hardware preparation and } \\
installation
\end{tabular}

\section{Additional explanations to the chart}

(The equipment costs were those in West Africa of hardware ordered from Europe by a local supplier):

a) A single computer is shared by employees for member operations, accounting and managing deposits and loans.

b) A power inverter is required to protect the computer against power variations and outages.

c) Minimum requirement is a laser printer for printing reports.

d) SAF licenses are required per operator site. Other basic licenses (Windows and MS Office) are included with the computer.

e) Air conditioning is required during hot seasons in West Africa in order to protect the computer.

f) According to the context and to ensure constant operation in times of power outages, a power generator is required.

g) Outlets are generally renovated at the same time as they are computerized. Tight doors and windows are required along with a counter that can hold the computer and ergonomic chairs are needed.

h) The Pocket PC unit includes all accessories including a backup battery and memory cards. The cost is US $\$ 1,000$ per unit.

i) Since the AMIO Teller outlet must serve as a processing center to synchronize data, $20 \%$ of computer costs were charged to that function (items a to f) since this environment is a prerequisite. One computer at a processing center can service 5 SAF databases.

j) The daily rate for an external trainer to introduce office productivity software is about US $\$ 35$. Training lasts at least 2 days per person. SAF training lasts 3 days and is delivered by the local IT team at a rate of US $\$ 27$ per day for the group. AMIO training lasts one day and is delivered by the local team to the group.

k) Knowing that all the sites must be converted to SAF for operations (an equal prerequisite) the efforts mentioned here only deal with preparing and installing equipment. This is performed by the local IT team and is set at about 3 days for an autonomous SAF environment (including ordering and tests) and 1 day for an AMIO environment.

I) After the launch date, operator support is provided by the local IT team at a rate of 10 days on site for SAF and 2 days on site for AMIO Teller. 
This brief analysis allows us to observe that introducing AMIO Teller cost three times less than introducing a desktop system. A computerization program must properly target sites before starting up operations. The analysis of the prerequisites noted in section 5 is also essential for proper decision making.

\subsection{Impact and benefits}

Since the context of mobile technologies associated with microfinance institutions is a new one, the real impact and benefits observed required several months to be seen after technical and organizational adjustments had been made. The impact and benefits were summarized and expressed in the form of a questionnaire and the answers were supplied by the experience provided by a year of operations.

\begin{tabular}{|c|c|}
\hline & AMIO Teller \\
\hline $\begin{array}{l}\text { Quality } \\
\text { service }\end{array}$ & $\begin{array}{l}\text { - The services in the outlet improved as member accounts were } \\
\text { immediately available (no need to search out member cards that had } \\
\text { been moved) and balances were up to date and reliable. }\end{array}$ \\
\hline Productivity & $\begin{array}{l}\text { - End of the day operations were limited to filling out the teller register and } \\
\text { filing documents to be sent to the processing center. } \\
\text { - Monthly closings were limited to audits. There were no items to } \\
\text { investigate. } \\
\text { - There were no more manual updates required for deposit sheets and loan } \\
\text { reimbursement sheets: entry operator errors disappeared, workload } \\
\text { decreased as did the time inspectors required to explain errors. }\end{array}$ \\
\hline
\end{tabular}

Does AMIO Teller contribute to projecting a modern image that reassures members and attracts new membership?

Members surveyed did not all react in the same manner.

- The Pocket PC is small and hardly visible behind the teller screen. Members apparently confused it with a calculator.

- If outlets equipped with AMIO Teller were not renovated (small run-down and poorly organized) even equipping them with desktop computers did not project a modern image.

When members well understood the role of mobile technologies in their coop they were very proud of the MFI and felt proud of the importance placed on quality of service that was being delivered.

\section{Does AMIO Teller contribute to reducing wait time for members?}

- With AMIO Teller, accounting entries still needed to be made: deposit and withdrawal slips and member passbooks needed to be filled out. Updating the member savings sheet was replaced by updating the member account in AMIO Teller. Most of the time AMIO Teller improved wait times due to the readily available updated information.

Does AMIO Teller help deliver services to communities that would not have been served otherwise?

- AMIO Teller is an interesting solution for mobile outlets. It offers the advantage of no longer having to transport and store savings deposit and loan reimbursement documents and eliminates the need to store and identify monthly reports. In addition, it is light and easy to carry when traveling. 
- In contexts where security is a manageable challenge and where the cost/benefit advantage is clear, AMIO may offer an interesting potential for providing efficient support for a mobile operation (for example using a vehicle to travel from village to village).

- The reduced cost of this type of implementation keeps transaction costs low thus helping to provide service to low income members.

\section{Does AMIO Teller produce tangible and measurable benefits?}

- If one refers to the above table and to the productivity gains mentioned, this could translate into staff reductions. Knowing that the staff is already minimal, the staff time recovered could instead be transformed into using those workers for business development activities.

- In the same vein, mobile technologies could be responsible for increased membership and more deposits and loans. But this situation is the result of a combination of factors, not just one. The Nyèsigiso modernization program, accompanied by the building of new coops and targeted communication efforts to certain populations are contributing factors that are much more important than AMIO Teller.

For AMIO Credit, the observations and comments received were used to produce the following table:

\begin{tabular}{|c|c|}
\hline & AMIO Credit \\
\hline Quality of service & $\begin{array}{l}\text { - Members indicated that the image of the network improved when loan } \\
\text { officers started using Pocket PCs and that the officers were better } \\
\text { informed and provided more precise answers on loan requests. } \\
\text { - In addition to shedding light on the type of intervention required for } \\
\text { overdue loans, AMIO Credit reportedly had an indirect impact on the } \\
\text { attitude of members who saw it as an indication of professionalism and } \\
\text { a serious approach. }\end{array}$ \\
\hline Productivity & $\begin{array}{l}\text { - Immediate access to updated information during recovery activities with } \\
\text { members. The information is available at all times. If loan officers } \\
\text { during their trips happen to encounter members with overdue loans } \\
\text { they are able to produce relevant data on reimbursement status. } \\
\text { - Autonomy in data collection. Without AMIO, loan officers must request } \\
\text { that tellers provide printouts of member statements. } \\
\text { - Personalized information per loan officer for recovery activities. The } \\
\text { loan portfolio of each loan officer is downloaded onto the Pocket PC at } \\
\text { a frequency set by the loan officer. } \\
\text { - Access to consolidate updated information allows them to devote only } \\
\text { one day to planning recovery efforts as opposed to } 5 \text { days previously. } \\
\text { The freed up time could be used for loan issuing meetings (a previously } \\
\text { neglected activity). } \\
\text { - With the information available using AMIO Credit, loan officers devote } \\
\text { much less time to producing monthly reports: } 1 \text { hour instead of } 8 \text {. } \\
\text { A tool adapted to the work environment of the loan officers and women } \\
\text { facilitators. The portability of AMIO Credit is perfectly adapted to the } \\
\text { work environment of loan officers who are out in the field most of the } \\
\text { time.. }\end{array}$ \\
\hline
\end{tabular}

This table highlights the two main impacts produced by AMIO Teller:

- The ways of doing things are optimized and efficiency is increased.

- Responsibility is strengthened and loan officers feel better equipped to do their work in a serious and rigorous manner. 
These are highly important impacts in the context in which sound credit management is a major concern that requires rigorous concentration by staff on value added activities. The impact could be measured and translated into benefits similar to those experienced for AMIO Teller. But since the emphasis has moved to more productive activities the effect will only be felt after several months if not after several years of operations using the tool.

\subsection{Lessons learned}

Based on the multiple activities and the challenges encountered, the project team has drawn up several lessons learned as guidelines for introducing innovative technology into microfinance networks:

- Since these new technologies necessarily bring major organizational and operational changes for many categories of employees, the organizational climate in the network must be very stable and the local staff must have full mastery of its fundamental roles (tellers, accountants, technicians). The skills of the local human resources are a crucial factor when introducing new systems. In addition, if the staff is too overloaded to assimilate a new system, any positive effects will be slow to appear.

- The benefits of technology use in general and mobile technologies in particular are very difficult to assess. It is known that computerizing operations in a savings and credit cooperative makes it possible to reduce the number of those performing manual operations. With technologies such as the Pocket PC, labor needs must be analyzed and recommendations made to reassign available resources. If this phase is not undertaken, the network cannot expect to reap the expected rewards.

- Despite very optimistic goals, it is difficult to reach poor populations in rural areas using technology although a little less so with mobile technologies. When hardware is located in environments far from major centers and in harsh environments (heat, dust, etc...) then support and maintenance efforts outweigh any benefits brought by technology. Funds must be made available to introduce a rugged infrastructure in these regions and staff with skilled resources. In Mali, in the northern areas (Tombouctou, Diré) upcoming deployments will demonstrate the feasibility of computerization in remote rural areas.

- The duration of a development project and the introduction of innovative technologies must last at least 5 years if the network is to be able to profit from support during all phases of its technological evolution. In the Nyèsigiso network in Mali, two years have just made it possible to lay sound foundations but several test projects will need to be supported with external technical assistance. It should be noted that there are very few projects using Pocket PC type technology and many lessons remain to be learned.

\subsection{Conclusion}

The interest shown by microfinance networks in technology is clear and has grown in recent months with the success in Mali which was the subject of presentations and demonstrations to MFI partners in countries in the West African subregion.

Mauritania has now introduced Pocket PCs and AMIO Teller into its computer systems with support from DID through the team of computer specialists located in Dakar, Senegal.

In Latin America where tests were run in 1999 using Palm Pilots for loan officers, Mexico has taken up the idea of AMIO Teller and equipped several sites with Pocket PCs. They added a portable printer to issue receipts for each transaction. Since DID developed the software so that it would be available in French, English and Spanish, it was easy to transfer this innovation into other microfinance institutions so that a maximum number of members could enjoy the benefits. 
Despite the ease of implementation and takeover of control by local teams, new needs and technologies are affecting the systems that have been developed and this calls for constant monitoring of mobile technologies. Due to the availability of GSM cellular networks, tools and peripherals that are constantly evolving and being added on a regular basis, and programs that are increasingly sophisticated means that portable technologies represent a constant challenge. If the number of partners developing local expertise continues to increase, and users become ever more proficient, if donor agencies provide support for innovative technological projects, the pool of knowledge will increase and what was a test project will become an effective, fully mastered, low cost system. This will benefit poor populations who will be integrated into their local economy through these tools adapted to their needs and aspirations.

In conclusion, the following statements come from individuals directly involved in this successful experiment.

\section{Abdoulaye DIAKITÉ, a member of a financial cooperative computerized with AMIO Teller in the Nyèsigiso network in Mali:}

"We are going to increase our coop membership for sure! People feel confident and know that their money is safe. When the word gets around, people join the coop and want to keep the institution in their own neighborhood."

\section{Cheick Oumar Tidiani KEITA, supervisor of the Computer services for the Nyèsigiso network in Mali:}

"Loan officers are now closer to the members. They get out seeing clients in the field carrying all their information on their Pocket PC. It is easy to use and my team has to provide very little support. Members are very pleased that their loan officers use modern tools." 